\title{
Re-claiming space for public life: messages from the north- western periphery of Sofia
}

\begin{abstract}
A case-study based qualitative research on public space and public life in four housing estates in the north-western periphery of Sofia provides the basis for re-thinking urban legacy and the Modernist concept of public interest, once placed in the core of urban planning. The expert estimation of the current physical state and functioning of open public space in the housing estates, initially developed from the 1960s to 1980s, is compared to current inhabitants' estimations of the potential of public space to respond to their needs and visions regarding its quality. The capacity and limitations of local inhabitants to articulate a common vision of public space in dialogue with experts and authorities are discussed. The authors claim that further urban research is needed to conceptualize present visions for public interest, public life, and public space in the transforming housing estates in Central and Eastern Europe in order to enhance the effectiveness of inclusive planning approaches for urban regeneration.
\end{abstract}

Keywords: urban research, public space, Modernist housing estates, Sofia, inclusive urban regeneration.

\section{Introduction}

A growing interest in the city and in public urban space is clearly visible in the present day. Initiatives in defence of public space in the city unfold at many levels - coming from the bottom-up, where local tensions focus on who uses it, and with what benefits and responsibilities; and from the top-down as part of the global political process. Nowadays, public space is a central topic in urban theory, policy, and practice (e.g. Benhabib, 1992; Angeles, 2010; UN HABITAT, 2016; Zárate, 2018; Riegler \& Bylund, 2020). This also raises questions on how inherited public space in the post-socialist housing estates (HEs) in the cities of Central and Eastern Europe (CEE) is currently being used and transformed, what are the perceptions of its inhabitants about its potential to respond to their visions regarding quality, and whose rights and responsibilities are considered in the dialogue of citizens, experts, and local authorities.

The study of ongoing processes in the open public space of four housing estates in the urban periphery of Sofia links the current functioning of public space, inherited from Modernist urban planning, to the inhabitants' perceptions of its potential to adequately respond to their needs, and to existing local capacity and motivation for creative action aimed at transforming the urban environment in dialogue between inhabitants, experts, and authorities. The global, EU, and national policy and research context of conceptualizing public space in Modernist housing estates is briefly outlined in Section 2. The aim and methodology of the undertaken study are presented in Section 3. The results are described in Section 4 and discussed in Section 5. Conclusions about the development potential of public space and needed further research in support of inclusive planning approaches for urban regeneration are drawn in Section 6. 


\section{Research framework}

\subsection{Public space in the cotemporary city}

Public space in the European city has been historically related to its capacity to enable human activities and to provide for access, encounter, and exchange. Contemporary western philosophical and political thought interpreted public space in its relation to the political process (Benhabib, 1992). The Modernist concept of the city, which played an important role in shaping the 20th-century urban environment, regarded public space as a key urban element of public interest (Mumford, 2019: 295). The birth of Modernism was related to the post-war situation in both Europe and the United States, with the building boom of the 1920s and 1930s providing strong arguments for standardization. Being true to the social promise of "adequate housing for all”, including residents of modest income, Modernist housing design turned to the achievements of technology but also accepted its social anonymity. It thus contributed to a situation where "normative programmes of accommodations and spatial organization also run the risk of curtailing precisely those non-specific spatial realms that seem to be the genius of truly well-functioning public places” (Rowe, 1993: 63). The major planning advantages of LHE were seen in the integrity of the engineering infrastructure, the abundant public greenery, and the presence of a set of key public service elements. Modernism also abandoned the traditional meaning of public space as one satisfying political, economic, and cultural needs, by being a place of assembly, a marketplace, and a place of rituals and ceremonies (Madanipour, 2004). The adoption of the "social space" notion in large housing estates shifted the focus on a single important function of public space where the key attractive environments are to be supported by proper management, maintenance and renewal, resident participation, and safety (Sendi at al, 2009). That partially raised Arendt's concern about the modern transformation of the public space of politics into a pseudo-space of interaction in which individuals no longer "act" but "merely behave" as economic producers, consumers, and urban city dwellers (Arendt, 1958: 56, cited in Benhabib, 1992: 90). The strongly deterministic functional doctrines were gradually abandoned in the Western countries by the late 1950s, and new intellectual concepts of the city as a complex dynamic system emerged (Alexander, 1964; Rapoport, 1969), with social sciences entering the urban planning field.

An important perspective of urban space as a socio-spatial construct was brought up by the "Right to the city" concept in the late 1960s (Lefebvre, 1967), which further evolved in urban theory and practice, and was recognized in legal instruments and public policies worldwide (Zárate, 2018). This concept also inspired the claim that "we can inhabit a world that includes our own praxis, meanings, values, signs and symbols, art and culture and not merely be forced to endure a habitat created for and imposed on us by those with power" (Zieleniec, 2018: 13). In the early 21st century, urban public space is valued for teaching tolerance and responsibility (Bodnar, 2001). It is claimed that "values, ideas, actions and spaces define one another and are constantly produced through each other" (Stevens, 2007: 218), and that people define the use and meaning of public space (Harrouk, 2020). The ongoing global political debate on development and resilience has acknowledged the key role of public space in contributing to sustainable and resilient urban development. The 2030 Agenda for Sustainable Development recognized the key role of cities and public urban space in the process. Target 11.7 explicitly requires "universal access to safe, inclusive and accessible, green, and public spaces, particularly for women and children, older persons and persons with disabilities" (UN HABITAT - SDG11, 2015: 21). The New Urban Agenda adopted at the United Nations Conference on Housing and Sustainable Urban Development likewise declared a commitment to "promoting safe, inclusive, accessible, green and quality public spaces that are 
multifunctional areas for social interaction and inclusion, human health and well-being, economic exchange and cultural expression and dialogue among a wide diversity of people and cultures” (UN HABITAT, 2016: 13). Public space is currently strongly supported by international initiatives from a cultural perspective, e.g. the European Prize for Urban Public Space (Angeles, 2010), and by international cultural organizations (UNESCO, 2016). In parallel, EU research programmes such as Horizon 2020 are increasingly interested in the various roles of urban public space while research results are integrated in EU urban policies to create spaces to mitigate shocks under a global pandemic (Riegler \& Bylund, 2020).

\subsection{The Modernist concept of housing and public space in the large housing estates in Central and Eastern Europe (CEE)}

Large housing estates have functioned for more than half a century under differing social and economic contexts across Europe being subject to complex socio-spatial transformations. The diversity in the formation and development trajectories of the housing estates in West and East European countries was strongly influenced by factors such as social and economic development, building period and size, location and connectedness, maintenance, population structure, stigmatization, etc. (e.g. Internet 1; Tsenkova \& Nedović-Budić, 2006; Brade et al., 2009; Anderson et al., 2013; Monclús \& Medina, 2016). The similarities are related to the fact that LHEs were designed and built everywhere in Europe to meet urgent social needs under economic restrictions by using the available construction technologies. The strict normative approach to urban planning and design in the housing field was aimed at socio-economic efficiency while guaranteeing the provision of a minimum standard of services and facilities for all. Although equipped with the basic social infrastructure, the vast plain urban landscapes in the LHEs provided anonymous public spaces that usually lacked human scale and cosiness. The outlined common characteristic of CEE housing estates concerns the sociocultural characteristics of their initial inhabitants (belonging to diverse social strata), despite the "constitution of the social and spatial meanings of large housing estates within [...] different national contexts" (Glasze et al., 2012:1192). Since 1975, the estimated deficiencies in LHE public places motivated top-down attempts in many CEE countries to rethink public life settings and the localization of public space (Marciniak, 2015).

In the early 1990s, the CEE-based researchers predicted systemic changes in the urban systems reflecting the profound political and economic transition in the region (Musil, 1993). Growing income inequalities and housing system transformations were registered in CEE cities by late 1990s and claimed to be the main causes for growing socio-spatial disparities (Sýkora, 1999). The land market was already reshaping the cities, while municipalities had difficulties in adopting strategies for suburban development (Bertaud, 2004). Around the turn of the millennium, doubts about the legitimacy of CEE planning were rising due to its lack of sensitivity to the local context when borrowing methods from abroad or applying old planning approaches (Nedović-Budić, 2001). Two decades after the start of the transition, researchers identified heavy social costs of the transition process under the context of an extremely weakened planning system (Hirt \& Stanilov, 2009). Positive development trends - improved institutional and legislative framework of urban planning, enhanced public participation in the planning process, and a declared explicit planning focus on sustainable development - were acknowledged in the CEE countries joining the European Union. 


\subsection{The prefabricated housing estates in Sofia: a contested legacy in transition}

The rapid industrialization of Bulgaria in the early 1960s triggered an urgent demand for urban housing, and large housing estates of prefabricated panel buildings were considered an optimal economic and social solution. The LHEs in Sofia were built mainly at the city periphery in a relatively short period to provide homes at affordable prices and meet housing shortage in the face of growing industrialization and intensified migration from rural to urban areas. The promoted collective housing resulted in sheltering under one roof people with diverse origin, education, way of life, and culture - immigrants from the countryside and local inhabitants. The first prefab housing estates in Sofia for 15,000-20,000 inhabitants each, with schools and kindergartens centrally located within walking distance in the neighbourhoods, were planned in the 1960s. In the mid-1970s, larger housing districts for up to 50,000 residents with planned healthcare and cultural facilities in the district centres were already under construction (Tashev, 1972). The next large housing estates, built in the mid-1980s, had up to 200,000 inhabitants (Kiradzhiev, 2006). According to the census from 2011, nearly half of the functioning housing stock in Sofia had been built between 1970 and 1990; prefabricated housing estates sheltered about 575,000 inhabitants, $47 \%$ of the city population (Internet 2 ).

The urban dimensions of Bulgarian transition after 1990 were related to class differentiation and to changes in land ownership due to privatization and restitution1 (Staddon \& Mollov, 2000). In parallel, local authorities lacked financial resources for the maintenance of LHEs. The general withdrawal of the State, the uncertain political context, and the outdated planning system postponed many of the planning activities for more than a decade (Thornley, 1993), despite the emerging new societal needs, conflicts, and challenges (Alexandrov, 2006). Transformations with negative impacts in the physical space of the large housing estates were motivated by market demand, unlocked by the restitution and privatization of urban land, and facilitated by the lack of effective planning instruments. The investment interest was higher in the LHEs in the southern and south-eastern peripheries of the city, and generated conflicts provoked a higher level of local activism there in defending the common asset - public open space. By the beginning of 2006 this form of resistance resulted in the emergence of up to 40 NGOs which integrated the knowledge and efforts of inhabitants, environmental activists, and urban experts (Grimm-Pretner et al., 2006).

\section{Research aim and methodology}

The present study stems from an on-going URBiNAT project (HORIZON 2020), focused both on the inclusive regeneration of social housing districts in several European countries and community driven design of healthy corridors in urban public space. Potential public space transformations are to improve access and mobility, promote healthy living environment, and experiment with inclusive planning and design approaches (Internet 3). The current study builds upon the analysis of the Bulgarian case study in URBINAT project - four neighbouring housing estates (HEs) in Nadezhda administrative district in the north-western periphery of Sofia (Figure 1), with overall 17,069 dwellings and 37,770 inhabitants in collective apartment buildings, mostly built between the 1960s and 1980s (Internet 2). The initial urban plans of the HEs have been updated during the last decade to respond to the changing situation in the neighbourhoods. The updated plans, adopted between 2013 and 2015, regulate the general access in the area without addressing issues of non-motorized mobility and accessibility in the neighbourhoods. The current study aims to link the current physical state and functioning of

1 Restored private ownership of urban and rural land property in Bulgaria, nationalized in the early 1950s. 
public space in the HEs to the inhabitants' perceptions of its quality, and the local capacity and motivation to articulate a creative common vision for needed transformations of the urban environment.

Three research questions (RQ) were raised: RQ1: What are the present-day physical state and functioning of public space in the housing estates? RQ2: How do residents and local authorities estimate the quality of public space and the effectiveness of its functioning and management? RQ3: What is the local motivation and capacity for implementing inclusive planning approaches to regenerate public space? The methodological framework of the study includes a variety of research methods for responding to each question (Table 1).
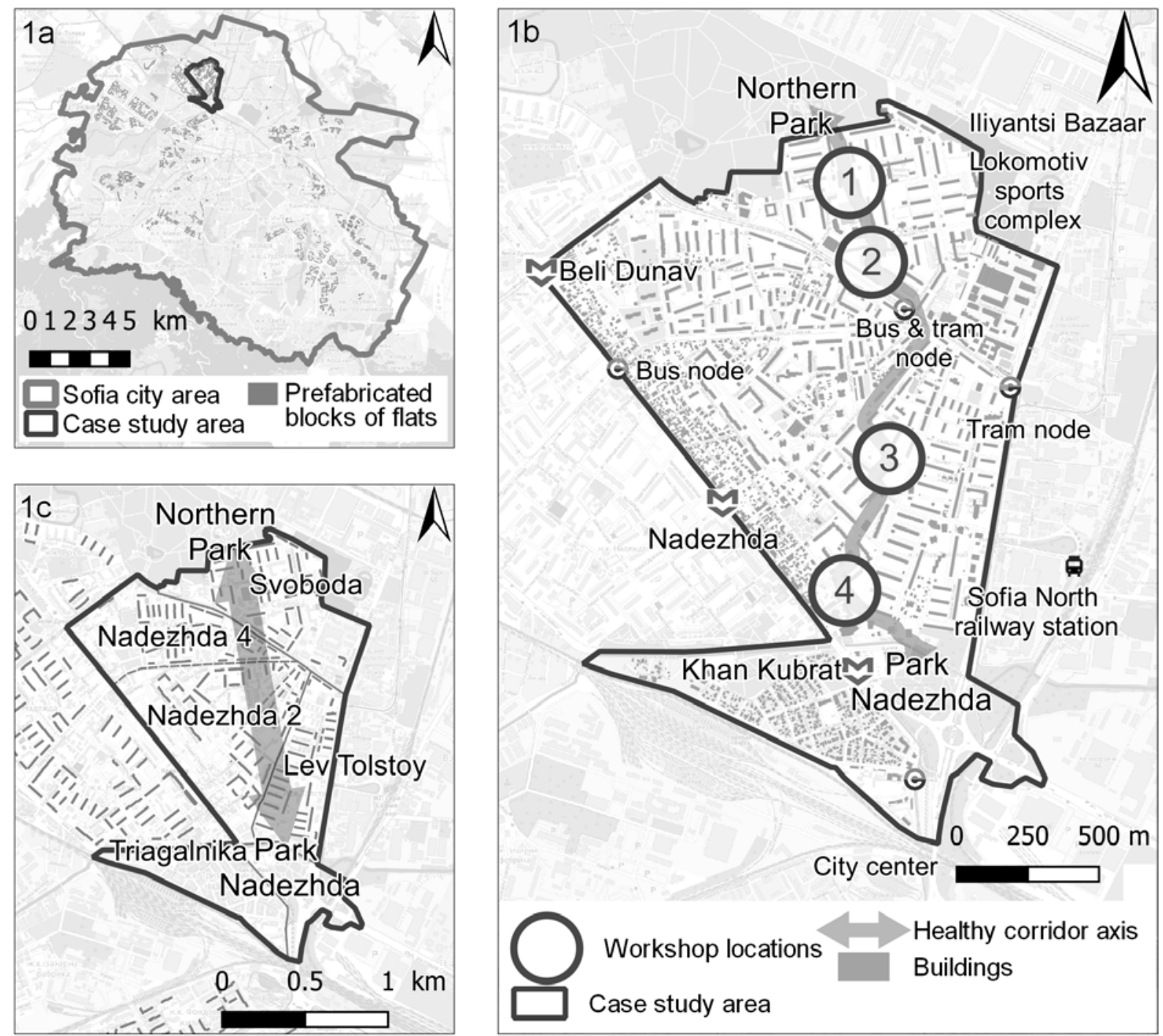

Figure 1 (the study area): 1a) location within the compact city of Sofia; 1b) healthy corridor area and co-design workshop locations; 1c) names and locations of the housing estates (based on: Internet 4; Internet 5). 
Table 1. Research methods applied

\begin{tabular}{|c|c|c|}
\hline Methods applied & Time interval & $\begin{array}{l}\text { Questions } \\
\text { addressed }\end{array}$ \\
\hline Direct expert observations and analysis & $\begin{array}{l}\text { Aug. } 2018 \text { - Sept. } \\
2019\end{array}$ & RQ1 \\
\hline Diachronic spatial analysis & $\begin{array}{l}\text { Oct. } 2018 \text { - Aug. } \\
2019\end{array}$ & RQ1 \\
\hline In-depth semi-structured interviews - 10 respondents. & Jun.-Sept. 2019 & RQ2, RQ3 \\
\hline Survey among citizens on the quality of life -440 respondents & Nov.-Dec. 2019 & RQ2, RQ3 \\
\hline "Walk through" and “photovoice” events & May 2019 & RQ2, RQ3 \\
\hline Focus groups -3 groups with overall 20 participants & Jun.-Sept. 2019 & RQ2, RQ3 \\
\hline Cultural mapping - 64 participants & $\begin{array}{l}\text { Aug. } 2018 \text { - Sept. } \\
2019\end{array}$ & RQ2, RQ3 \\
\hline $\begin{array}{l}\text { Motivational interviews (pupils - } 30 \text { respondents, district } \\
\text { administration }-4 \text { respondents) }\end{array}$ & May 2019 & RQ2, RQ3 \\
\hline Territorial mapping (inventory of furniture, paths, and greenery) & $\begin{array}{l}\text { Oct. } 2018 \text { - Aug. } \\
2019\end{array}$ & RQ1 \\
\hline Behavioural mapping & May-Jun. 2019 & RQ1 \\
\hline $\begin{array}{l}\text { On-site co-design workshops with citizens - } 4 \text { workshops with } \\
140 \text { overall participants }\end{array}$ & Aug.-Sept. 2020 & RQ2, RQ3 \\
\hline
\end{tabular}

Diachronic spatial analysis, based on desk research and territorial mapping, was chosen to identify the changes in land ownership and the spatial transformations of open space and street patterns since the first Modernist housing estates had been developed in the area in the 1960s. The expert estimation of the current state and functioning of public space concerned the quality of the built and natural environment. The chosen key aspects of the built environment included accessibility (openness and permeability), usability (physical state and maintenance), functionality (diversity of users and uses), comfort of use (soundscape, lighting, shading, urban furniture), and safety and security (conflicts of use and vandalism). The key elements of the natural environment comprised air quality, water, and public greenery. These results were supposed to provide the ground for estimating the effectiveness of public space management. Expert observations following the methodology of Gehl Institute (Internet 6) were chosen for the evaluation of ongoing public life in the open spaces: types of activity, actors, and temporal intervals. The results regarding public life were then related to residents' and authorities' views on the quality of public space and its management. Citizens' proposals for urban design intervention registered during four onsite co-design workshops in the neighbourhoods provided the basis for identification and estimation of existing local motivation and capacity for inclusive urban planning and design.

\section{Results}

\subsection{Expert estimation of the physical state and functioning of public space}

The street network, the residential buildings delineating the public open spaces, and the schools and kindergartens located within the urban units had a major long-term effect on the housing estates development. The main elements not realized until 1990 were the two green axes, linking Nadezhda 4 and Svoboda HEs with the Northern Park (Bg. Severen park) and Svoboda HE to the sports area to the east. After 1990, the main pedestrian access from the housing estates to the park and to the sports area has been compromised due to construction on the non-built- 
up plots and the public greenery along the street sidewalks. The initially designed sidewalks and alleys - together with the non-formal pathways through the greenery and non-utilized plots - currently provide numerous pedestrian mobility options in the area (Internet 7).

The outlined positive aspects in the built environment include the visible presence of people in public space and the considerable variety of users and uses throughout the day. Pedestrian mobility and socializing are observed in most of the public places. Sidewalks, inner streets, alleys, and informal paths are intensively used by pedestrians. The daily use of some of the sites is gender-specific; others are equally preferred by men, women, and children. Individuals or small groups use parts of the space around the residential buildings for small flower gardens. The small kiosks at the bus stops and street intersections are intensively visited and crowded, despite high noise levels and polluted air. Most of the sites inside the area offer basic comfort for standing, sitting, and moving. The residents have followed a long-established tradition and adapted sitting places to their needs (Figure 2). Negative tendencies are related to the appearance of fenced plots and sports facilities with restricted use, which have reduced the accessibility and permeability of public space in some parts of the area. The lack of adequate parking area has caused considerable pressure on the public greenery and additionaly contributes to air and noise pollution (Figure 3). The inner street sidewalks and street crossings are badly maintained and rather unsafe to use, especially by vulnerable, disabled, and elderly groups; no cycling lanes are provided. Lighting is largely missing inside the area; shading and greenery are missing in the busy places around public transport stops and playgrounds. The management of both the built and natural environment in the study areas was generally estimated as unsatisfactory.

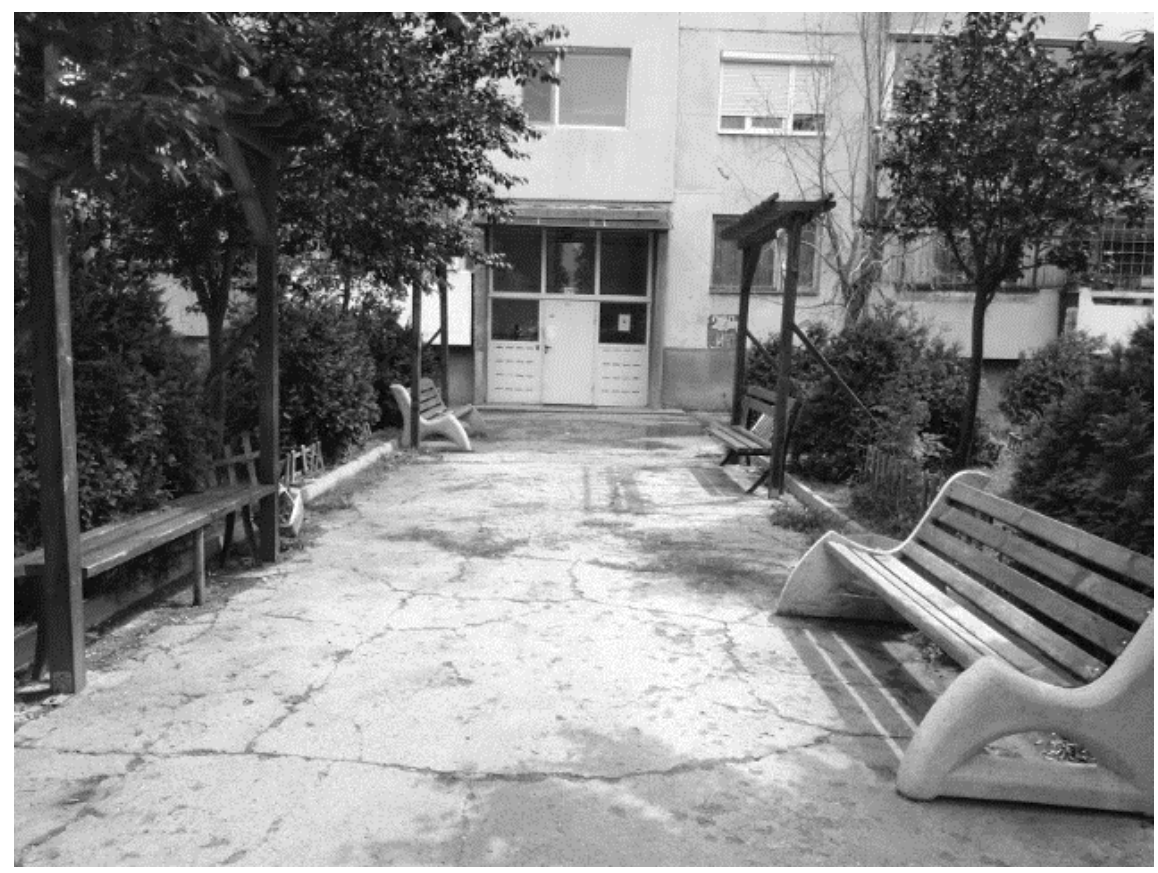

Figure 2: Sitting places in front of a block entrance (photo: authors) 


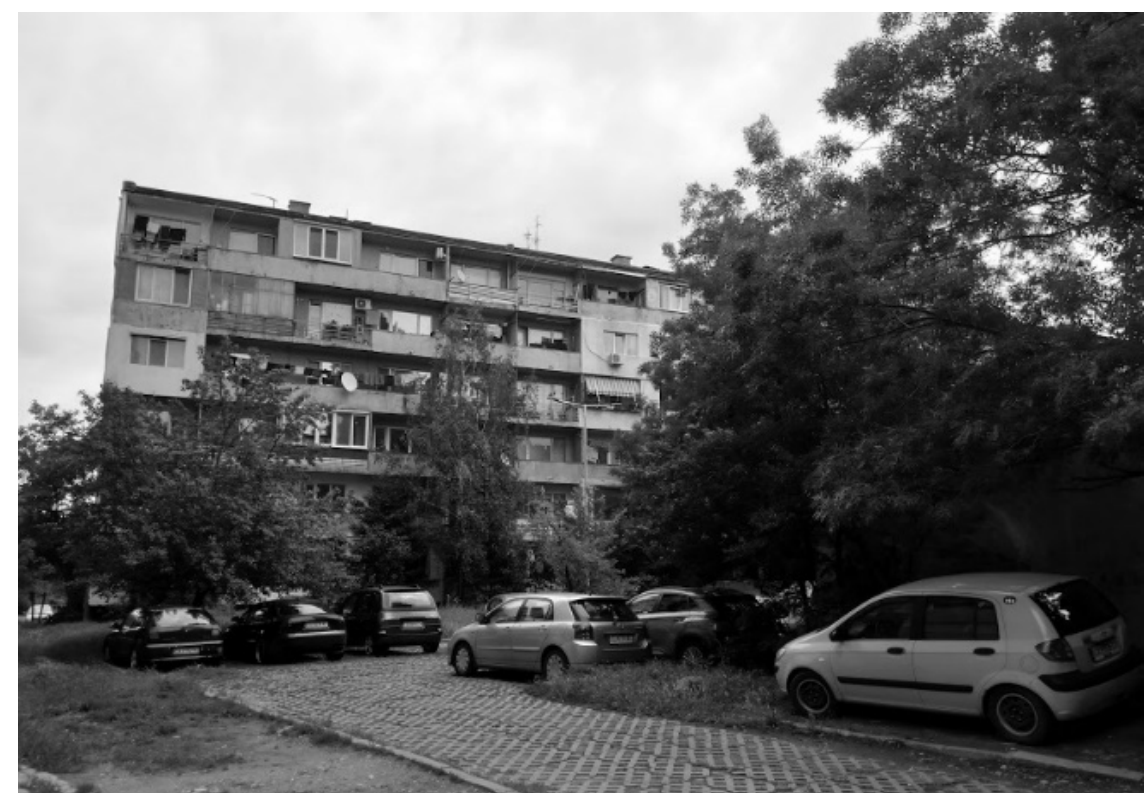

Figure 3: Cars parked in the inter-block space (photo: authors)

\subsection{Inhabitants’ perceptions of the quality and management of public space}

Inhabitants ranked highly several groups of urban elements in the HEs public space: the public parks and gardens in the area, used for daily or weekly recreation, and well maintained and landscaped by the municipality; inter-block spaces, broadly estimated as important for their proximity and favourable microclimatic characteristics; the meeting places with benches in front of the residential buildings, regularly used and maintained by some of the inhabitants; the main streets and their sidewalks, considered well-functioning and highly permeable; the metro line set into operation in 2012, estimated to provide an excellent connectivity to the city centre. Inhabitants' satisfaction with the environmental components relates inversely to the location within the neighbourhoods; e.g. the air quality and noise levels are considered very unsatisfactory at the edges and very satisfactory in the inner parts. Small meeting places attract people and are run by local communities (spaces in front of entrances, children's playgrounds, or sports facilities) or private entities (cafes, restaurants, and shops). The people involved in voluntary day-to-day management of the public space near their blocks of flats have developed a sense of ownership and tend to restrict outsiders' access. Inter-block spaces, when perceived as "nobody's space", receive minimal care by the local authorities. Despite being welllandscaped, spacious, and with many trees, they are estimated as unsatisfactory because of the poor maintenance of the greenery and the scarce, missing, or damaged furniture for sitting and relaxation. Survey respondents gather around the need for better protection of the natural environment - air, soils, vegetation, biodiversity, water - and improvement of waste management. Some people insist on providing more parking places, while others are concerned about the negative effects of the increased parking in the area. The schoolyards are popular meeting and playing places; it is acknowledged that the renovated ones provide excellent conditions, but the limited access is disappointing. The management responsibilities there are delegated to private companies. Inhabitants are sensitive to cases of obvious infringement of residents' rights, such as green space being built up, a playground turned into a parking area, a one-storey house replaced by a high-rise building, but also to activities that cause overcrowding or a green space generating light pollution, noise, and waste after having been turned into a playground. 


\subsection{Local visions for needed public space transformation and motivations for social action}

The four locations of the onsite co-design workshops (WS) were on plots of public ownership and with estimated capacity for future interventions: WS1 - by the entrance of the Northern Park; WS2 - by a currently non-functional privatized service building; WS3 - by a captured mineral spring with non-drinkable water; WS4 - close to the main pedestrian access to Nadezhda Park (Figure 4). The 140 overall participants (89 female and 51 male) who joined in the workshops were asked to propose interventions which would improve the quality of a particular public space. The results of the co-design workshops could not be considered representative of all the residents' visions and preferences for public space in the area.2 However, they seem to be indicative of certain shared values and priority needs in the area. For the aim of the current study, the registered 150 proposals were classified into 3 groups concerning: mobility and comfort of use (55 proposals), healthy living (physical activity and contact with Nature) (105), and social action and interaction (85). The most frequently proposed ideas comprised vertical green walls (51), educational gardens3 in schoolyards and kindergartens (32), the provision of smooth surfaces and adequate lighting for pedestrians and bicycles (23), and a thermal water swimming pool (18). The proposals also included farmers' and solidarity markets, leisure activities (art exhibitions, an open-air theatre), improvements of meeting places in front of the entrances. Based on the work with citizens during the on-site workshops, the study outlined several types of inhabitants' attitude to social action for transforming public space: (a) actively addressing certain problems (a rather limited group, with most of them already involved in ongoing initiatives); (b) ready to join if invited, with asking for further guidance; (c) reluctant to join in activities considered to be a responsibility of the municipality; (d) unwilling to be bothered; (d) providing advice and proposing solutions yet unwilling to be involved in practical action; (e) suspecting a hidden agenda behind the project initiatives; (f) easily disappointed when things do not happen immediately.

\footnotetext{
2 Results were also influenced by URBiNAT suggestions for nature-based solutions (NBS), made in advance.
}

3 Tasty Gardens of Learning (Internet 8). 


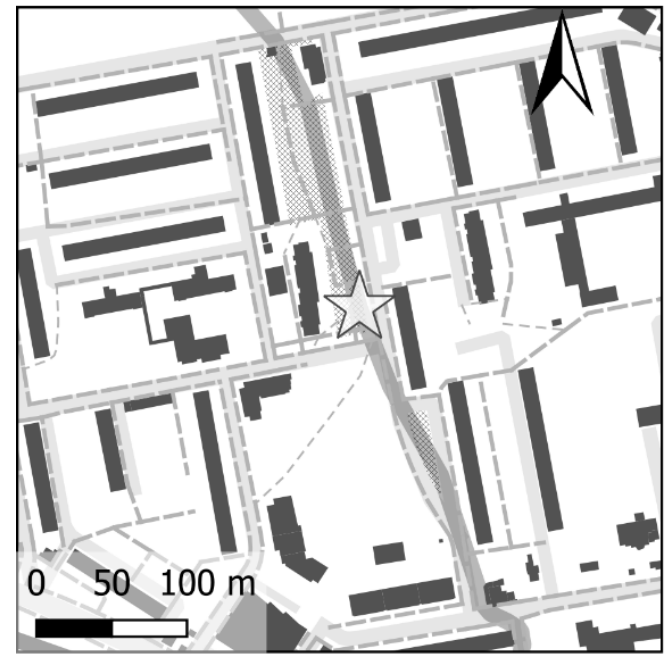

WS1 number of proposals by type:

$\bigcirc 15 \bigcirc 31 \bigcirc 29$

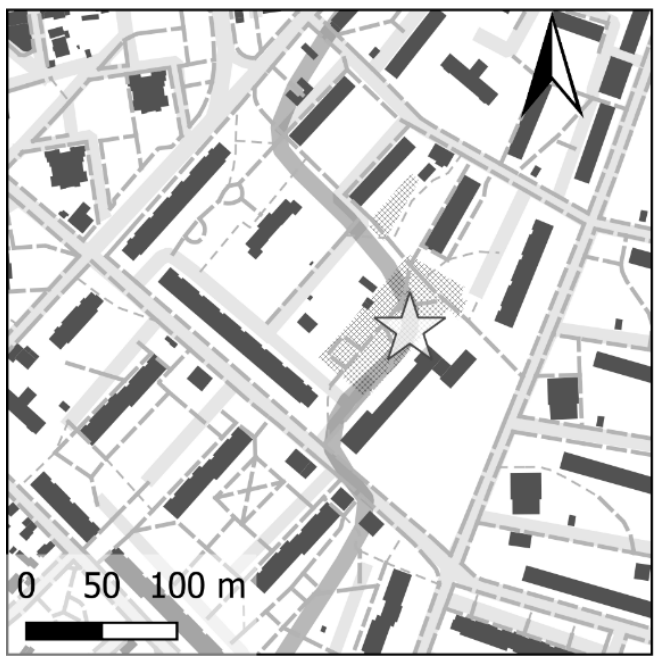

WS3 number of proposals by type:

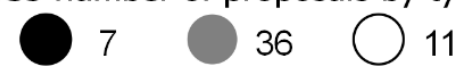

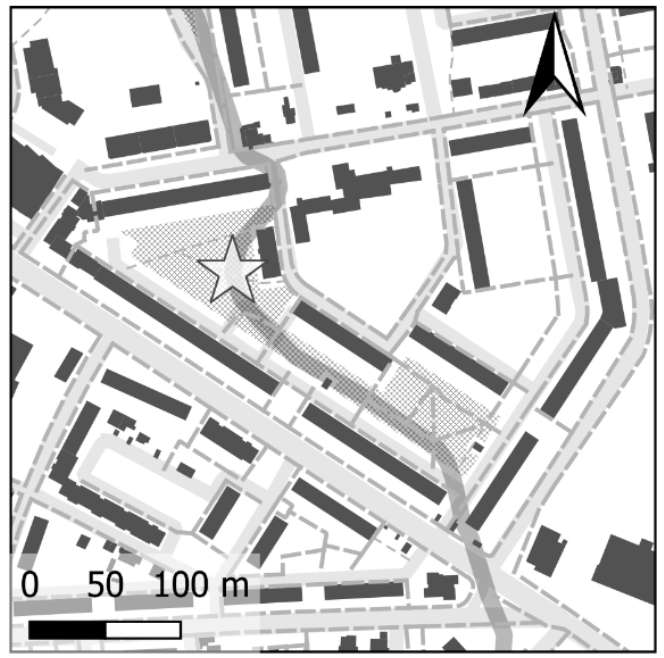

WS2 number of proposals by type:
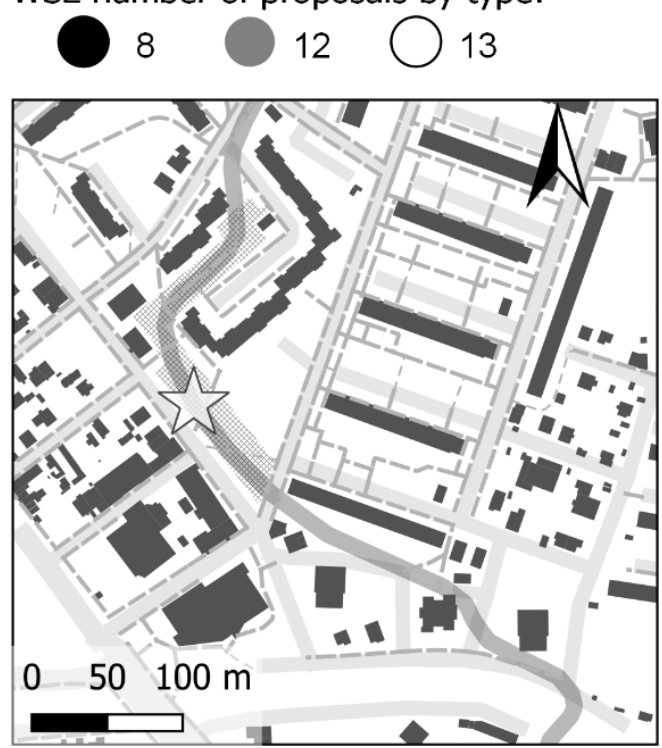

WS4 number of proposals by type:

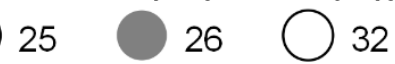

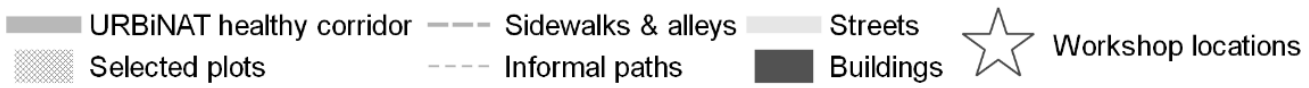

Figure 4 Workshop locations and typology of inhabitants' proposals for interventions in public space. Number of inhabitants' proposals by type: access and comfort of use (black); healthy living (grey); and social action and interaction (white) (illustration:authors).

\section{Discussion}

The analysis of data, on-site observations, and participatory events enable an understanding of the role and transformation potential of current public space. Linking the outlined important characteristics of public space and public life in the LHEs to the inhabitants' perceptions of public space quality provides an insight into the current inhabitants' concept of public space and its influence on their motivation and capacity for social action. 


\subsection{Public space in the present-day housing estates: role and transformation potential}

Three decades after the collapse of a society which proclaimed the priority of public to private interest, the transforming LHEs are open socio-spatial systems, influenced by numerous external factors that strongly stimulate population dynamics and challenge the territorial cohesion at hand: the ongoing social stratification of society, the development of the real estate markets, the opening of the capital city of Sofia to newcomers from the countryside or abroad with their diverse culture, values, and lifestyles. The concept of public interest has evolved alongside societal transformations in time of dynamic formal or informal, planned or spontaneous change of communities and space.

The expert analyses confirmed that the public space in the HEs is still physically abundant, multifunctional, and liveable. Contrary to existing prejudices about life in the "dormitory type" residential areas and despite the identified deficits in the physical state and maintenance, the public spaces in the studied LHEs shelter diverse public life activities. Although intensive and multi-layered, with established rhythms and meeting points, the public life in the LHEs is rather fragmented into numerous places due to the dispersed location and discontinuity of the public plots, the poor amenities, and the existing barriers such as abandoned and non-maintained private plots. Public life is interwoven into residents' daily activities. The specific atmosphere in the neighbourhoods and the community spirit there are shaped by the prevailing pedestrian walking and biking. There is no public place explicitly intended for teenagers in the housing estates, and only scarce places for public gathering and entertainment; few cultural activities are organized in the open space. There is a general lack of large public gatherings of all the residents in open space; only small communities gather at specific places. The cultural perceptions of public life and public space are also specific for different generations - the elderly enjoy everyday socializing in public space, while teenagers prefer to communicate in virtual space. The lack of established rules and proper organization of use are major risk factors for a decreasing quality of life in the neighbourhoods. The number of workshop participants in the different locations of the housing estates could also be considered as indicative for the importance residents attribute to different public places in the neighbourhoods.

\subsection{The LHE inhabitants' concept of public space}

Present-day population of the housing estates includes people with diverse paths of life and a broad variety of incomes and qualifications. Many of the inhabitants have scarce or no memories of the time of socialism. However, some of the blocks of flats in Nadezhda District are occupied by second or third generation residents who have grown up together with the HEs, and their history and memories are locally rooted in the changing urban environment. The most often declared topic of common interest during the on-site contacts in the north-eastern periphery of Sofia is public health. It is seemingly able to integrate the diverse values, needs, and aspirations of all the actors. Contacted inhabitants acknowledge the important beneficial impact of open public space on the health and wellbeing of individuals and communities. They mention clean air, access to greenery, calmness and cleanness, physical and psychological comfort, access to services, safety and security, and urban infrastructure in support of sports and physical activity among the valued determinants of health and healthy urban environment. Yet, positioning all these in relation to needed common choices on local development seems difficult. The commodification of public space is one of the most controversial transformations threatening the democratic dimension of public space and bringing new emphasis to the still open question about "whose city" it is. Property rights, highly valued in a neo-liberal society, have brought a shift towards a model prioritizing the economic value of public space, leading 
to negligence and appropriation of (quasi-) public spaces, and turning them into either "no man's land" or into "club" places with restricted access. The researchers' contact and interaction with the residents and authorities in the housing estates indicated a considerable misbalance in their acknowledging of public and private interest. People more readily distinguish their personal rights, and they are much more prepared to stand for those than for their responsibilities to a community. Moreover, rights and obligations are differently perceived and based on diverse arguments, thus bringing tensions and inspiring competition for the utilization of public space. The role of collective land ownership under the changing property context in the HEs is a topic still in need of debate. There is a major mismatch between authorities' and citizens' views on public space management. On the one hand, the district administration staff acknowledges the importance of working with citizens in transforming public space, but this is also seen as quite a challenge; the lack of penalty mechanism isperceived as the main reason for the poor state of the inter-block spaces. On the other hand, inhabitants claim they need to be better informed, guided, and instructed in order to participate in activities organized by the authorities. The analyses outline a variety of multi-layered conflicts concerning mobility conditions and practices, and serious clashes of different interests. There are contradictory and conflicting claims by car-owners, pedestrians, cyclists, and motorists regarding the right to public space. The tensions were explicitly deep when discussing the "right" to park private cars on green and underused areas due to the lack of parking places. Inhabitants react sharply against the change of functions and the resulting transformations of public space, especially when free access to public assets is threatened. Conflicts deepen with the appearance of new actors, and citizens' distrust only grows when a replacement of activities and uses happens on the quiet.

\subsection{Local capacity to articulate a common vision of public space and jointly stand for it}

During all the interactions, residents, pupils, and district administration expressed their interest in and commitment to the co-creation of public places. Children were seen as influential "channels" for shaping opinions and motivating parents' action in the neighbourhoods; pupils demonstrated readiness to participate in the cleaning of public space and in building or repairing street furniture if guided and instructed in how to perform. Although young people (aged 1927) stated their readiness to participate in the process, they refrained from being organized and guided; instead, they were rather ready to act spontaneously and without postponement. Inhabitants broadly see a healthy living environment as a priority; they highly value public greenery and care for it. Despite the abundant greenery in the area, the intervention proposals are largely focused on vertical green walls as an affordable and easy way to structure large open spaces into smaller units, provide for greater cosiness, and hide ugly urban elements. The estimated importance of Nature for a healthy life was also the reason for the high popularity of the Tasty Gardens of Learning as an educational tool to enable the transfer of values to children. Residents value walking within the housing estates and insist that safety and comfort of the practice should be provided for. The availability of the thermal mineral water in the area has long been acknowledged and broadly associated with an opportunity for a school swimming pool. Presently, concerns are already emerging about construction and maintenance costs, and the consequences of a possible public-private partnership to provide funding needed. The workshops have also revealed participants' initial general lack of self-confidence when sharing an idea in public. There is a broadly shared expectation that local administration should take the initiative to propose certain action, and inhabitants would then either accept or criticize it. Despite a certain lack of trust in top-down initiatives coming from outside, the process of building a joint vision for the interventions in the target area between the inhabitants and the administration resulted in strengthening public awareness of the potential of urban public space 
and needed joint action for re-claiming it. The declared good will for collaboration could be expected to provide a solid ground for future action, but strategic thinking and communication skills are currently lacking. A clearer communication for conceptualizing the value of public space among all the participants could be expected to enable a clearer vision on needed strategic action for its achievement.

\section{Conclusion}

A century ago, Modernism placed public interest in the centre of urban planning concerns. It promoted collective living and public space for all but stood in defence of an abstract concept of "public" in which public ownership equalled state ownership. In the numerous housing estates designed and built in Bulgaria, the diversity of inhabitants and their needs was never really considered. Thus, uniformity of urban design reflected and encouraged uniformity of life. Thirty years after the beginning of the political and socio-economic changes in CEE, research findings about the changing character of public space and public life in the housing estates in the north-western periphery of Sofia provide evidence that, although having a difficult legacy to deal with, the HEs have successfully taken their paths to the future. In this process they are facing serious deficits and challenges but have also demonstrated remarkable resilience probably rooted in the social diversity of their initial and current residents. Despite maintenance shortcomings and visible signs of degradation, the public places in the housing estates are nowadays vital and responding to changing lifestyles and value systems, to social needs and environmental challenges. They preserve the potential for being truly public space - in Arendt's words, the space where "men act together in concert" (Arendt, 1961: 4, cited in Benhabib, 1992: 93). The discussion on public space and public life initiated by URBiNAT project drew the attention of citizens and authorities to the need to think more strategically about the present and future of public space. However, re-claiming space for public life through democratic urban governance still has a long way to go. Inclusive planning and creative co-design for urban regeneration with citizens will be effective tools only if processes are based on mutual trust and respect, and organized according to clear planning rules and communication strategies.

Milena Tasheva-Petrova, Department of Urban Planning, Faculty of Architecture, University of Architecture, Civil Engineering and Geodesy, Sofia, Bulgaria (tasheva_far@uacg.bg)

Elena Dimitrova, Department of Urban Planning, Faculty of Architecture, University of Architecture, Civil Engineering and Geodesy, Sofia, Bulgaria (eldim2002@gmail.com)

Angel Burov, Department of Urban Planning, Faculty of Architecture, University of Architecture, Civil Engineering and Geodesy, Sofia, Bulgaria (burov_far@uacg.bg)

Irina Mutafchiiska, Department of Urban Planning, Faculty of Architecture, University of Architecture, Civil Engineering and Geodesy, Sofia, Bulgaria (irina.mutafchiiska@gmail.com)

\section{Acknowledgments}

This research is grounded on URBINAT project studies (Horizon 2020, contract No 776783). The authors would like to express their gratitude to the teams from Sofia municipality and Nadezhda administrative district, to all 
colleagues and inhabitants involved in the fieldwork and the participatory events, and to the two reviewers of the initial manuscript version for their critical comments and valuable suggestions.

\section{References}

Alexander, C. (1964) Notes on the synthesis of form. Cambridge, MA, Harvard University Press.

Alexandrov, A. (2006) Prehodniat period v gradoustrojstvoto [The transition period in urban planning]. Institut za modernostta, Sofia.

Andersen, H.T., Dimitrova, E., Schmeidler, K. (2013) Urban knowledge and large housing estates in Europe. In: Andersen, H. T., \& Atkinson, R. (eds.) Production and use of urban knowledge: European experiences, pp. 103-132. Dordrecht, Springer. DOI: 10.1007/978-90-481-8936-6_6

Angeles, M. (ed.) (2010) In favour of public space: Ten years of the European prize for urban public space. Centre de Cultura Contemporania de Barcelona, ACTAR.

Arendt, H. (1958) The human condition. Chicago, University of Chicago Press.

Benhabib, S. (1992) Models of public space: Hannah Arendt, the liberal tradition and Jürgen Habermas. In: Situating the self: Gender, community and postmodernism in contemporary ethics, pp. 89-120. Cambridge, Polity Press. DOI: 10.4324/9781003059516-5

Bertaud, A. (2004) The spatial structures of Central and Eastern European cities: more European than socialist? In: Winds of societal change: Remaking post-communist cities. International conference proceedings. Urbana, IL, University of Illinois at Urbana-Champaign.

Bodnar, J. (2001) On fragmentation, urban and social. In: Fox Gotham, K. (ed.) Critical perspectives on urban redevelopment. Research in urban sociology, 6, pp. 173-193. DOI:10.1016/S1047-0042(01)80008-8

Brade, I., Herfert, G., Wiest, K. (2009) Recent trends and future prospects of socio-spatial differentiation in urban regions of Central and Eastern Europe: A lull before the storm? Cities, 26(5), pp. 233-244. DOI:10.1016/j.cities.2009.05.001

Glasze, G., Pütz, R., Germes, M., Schirmel, H., Brailich, A. (2012). The same but not the same: The discursive constitution of large housing estates in Germany, France, and Poland. Urban Geography, 33(8), pp. 1192-1211. DOI: 10.2747/0272-3638.33.8.1192

Grimm-Pretner, D., Rode, P., Dimitrova, I., Dandolova, I., Hadji Pecova, S., et al. (2006). Activating the potentials of public urban green spaces. Unpublished report. Sofia, Austrian Science and Research Liaison Office (ASO), Centre for Social Innovation.

Harrouk, C. (2020) Public spaces: Places of protest, expression, and social engagement. Available at: https://www.archdaily.com/941408/public-spaces-places-of-protest-expression-and-social-engagement (accessed 20 April, 2021).

Hirt, S. \& Stanilov, K. (2009) Twenty years of transition: The evolution of urban planning in Eastern Europe and the former Soviet Union, 1989-2009. Nairobi, UN-HABITAT.

Internet 1: https://cordis.europa.eu/project/id/EVK4-CT-2002-00085

Internet 2: http://www.nsi.bg/census2011/pageen2.php?p2=179 (accessed 27 April 2021).

Internet 3:,https://www.urbinat.eu (accessed 28 April 2021).

Internet 4: https://kais.cadastre.bg/en/Map (accessed 14 Dec. 2020).

Internet 5: https://www.openstreetmap.org (accessed 14 Dec 2020).

Internet 6: http://www.gehlpeople.com (accessed 29 April 2021).

Internet 7: http://www.isofmap.bg (accessed 14 Dec. 2020).

Internet 8: https://gradinka.zaedno.net (accessed 29 April 2021).

Kiradzhiev, S. (2006) Sofia 125 godini stolica 1879-2004: Letopis [Sofia 125 Years Capital 1879-2004: Chronicle], Sofia, IK Gutenberg.

Lefebvre, H. (1967) Le droit à la ville. L'Homme et la société, 6(1), pp. 29-35. DOI: 10.3406/homso.1967.1063

Madanipour, A. (2004) Marginal public spaces in European cities. Journal of Urban Design, 9(3), pp.267-286. DOI: $10.1080 / 1357480042000283869$

Marciniak, P. (2015) From social housing estate to urban community: Public space in residential estates in Poland after 1945. In: Harnack, M., Haumann, S., Berkemann, K., Tvrtkovic, M., Wolf, T. M., Herold, S. (eds.) Community spaces: Conception, appropriation, identity. Proceedings of the 2nd conference of Netzwerk 45+, pp. 43-54. Berlin, Universitätsverlag der TU Berlin. Available at: http://nbnresolving.de/urn:nbn:de:kobv:83-opus4-60470 (accessed 25 April 2021).

Monclús, J. \& Medina, C. D. (2016) Modernist housing estates in European cities of the Western and Eastern Blocs. Planning Perspectives, 31(4), pp. 533-562. DOI: 10.1080/02665433.2015.1102642

Mumford, E. (2019) CIAM and its outcomes: Commentary. Urban Planning, 4(3), pp. 291-298. DOI: 10.17645/up.v4i3.2383

Musil, J. (1993). Changing urban systems in post-communist societies in Central Europe: Analysis and prediction. Urban Studies, 30(6), pp. 899-905. DOI: 10.1080/00420989320080841 
Nedović-Budić, Z. (2001) Adjustment of planning practice to the new Eastern and Central European context. APA Journal, 67(1), pp. 38-52. DOI: 10.1080/01944360108976354

Rapoport, A. (1969) House, form and culture. Englewood Cliffs, NJ, Prentice-Hall.

Riegler, J., Bylund, J. (eds.) (2020) Unfolding dilemmas of urban public spaces: Recommendations by JPI Urban Europe's AGORA. Policy paper. Available at: https://jpi-urbaneurope.eu/wpcontent/uploads/2020/10/AGORA_PublicSpaces_PolicyPaper_Online.pdf (accessed 29 April 2021).

Rowe, P. (1993) Modernity and housing. Cambridge, MA, MIT Press.

Staddon, C., B. Mollov (2000). City profile - Sofia, Bulgaria. Cities, 17(5), pp. 379-387. DOI: 10.1016/S02642751(00)00037-8

Stevens, Q. (2007). The ludic city: Exploring the potential of public spaces. London, New York, Routledge. DOI: $10.4324 / 9780203961803$

Sýkora, L. (1999) Processes of socio-spatial differentiation in post-communist Prague. Housing Studies, 14(5), pp. 679-701. DOI: 10.1080/02673039982678

Tashev, P. (1972). Sofia - arhitekturno gradoustroistveno razvitie: etapi, postijenia, problemi [Architecture and urban development of Sofia: Stages, achievements, problems], Sofia, Tehnika.

Thornley, A. (1993). Sofia: Building the foundations for a market-oriented planning system in Bulgaria. Planning Practice \& Research, 8(4), pp. 27-30. DOI: 10.1080/02697459308722900

Tsenkova S. \& Nedović-Budić, Z. (eds.) (2006) The urban mosaic of post-socialist Europe: Space, institutions and policy. Heidelberg, New York, Physica-Verlag. DOI: 10.1007/3-7908-1727-9

UN HABITAT - SDG 11, Available at https://www.unfpa.org/sites/default/files/resourcepdf/Resolution_A_RES_70_1_EN.pdf (accessed 29 April 2021).

UN HABITAT (2016). The New Urban Agenda. Available at: https://habitat3.org/wp-content/uploads/NUAEnglish.pdf (accessed 05 May 2021).

UNESCO (2016) Culture: Urban future. Global report on culture for sustainable urban development. Manual. Paris, UNESCO Paris. Available at: http://openarchive.icomos.org/1816/ (accessed 29 April 2021).

Vision for Sofia (2018) Study of the pedestrian connectivity in Sofia. Available at: https://vizia.sofia.bg/2019/02/21/pedestrian_network/ (accessed 21 Dec 2020). [Izsledvane na peshehodnata svarzanost na teritoriata na Sofia].

Zárate, L. (2018) The Struggle for right to the city and the New Urban Agenda. In: Randhawa, P. (ed.) The New urban agenda: Prospects and challenges, pp. 9-37. Citizen’s Rights Collective, ActionAid India, New Delhi.

Zieleniec, A. (2018) Lefebvre’s politics of space: Planning the urban as oeuvre. Urban Planning, 3(3), pp. 5-15. DOI:10.17645/up.v3i3.1343 